SEMBLANZAS 



\title{
SEMBLANZA DE FRANCISCO TOMÁS Y VALIENTE
}

\author{
MANUEL ARAGÓN REYES \\ Catedrático de Derecho Constitucional \\ Universidad Autónoma de Madrid
}

SUMARIO

I. Una semblanza merecida. II. El significado de un asesinato. III. Francisco Tomás y Valiente como miembro del Tribunal Constitucional. IV. Francisco Tomás y Valiente como constitucionalista. V. La validez actual de su figura.

\section{UNA SEMBLANZA MERECIDA}

En la serie de semblanzas de maestros del Derecho Político (o Constitucional) español que se han venido publicando en esta Revista y creo que debía figurar la de Francisco Tomás y Valiente. No sólo por su trayectoria intelectual, sino también por el importante significado que alcanzaron su ejemplo personal e institucional y su trágica muerte. No fue, en el plano universitario, un profesor de Derecho Constitucional, sino un historiador del Derecho, pero ejerció además, y sin duda alguna, como constitucionalista reputado.

Al estudio y a la aplicación de la Constitución dedicó los mejores años de su vida, dando una muestra impagable de servicio a nuestro Estado de Derecho democrático y social. Merecía, pues, figurar en el elenco de semblanzas que, en mi opinión, con tanto acierto ha promovido esta Revista con el objetivo de recordar a nuestros maestros y procurar así que el ejemplo que nos dieron se mantenga vivo entre las nuevas generaciones de juristas que, herederos del viejo Derecho Político, ahora se dedican al Derecho Constitucional. Un Derecho éste que no puede comprenderse ni aplicarse rectamente sin tener en cuenta que su rigor jurídico-dogmático ha de ir acompañado de las necesarias reflexiones que la historia y la teoría política proporcionan.

\section{EL SIGNIFICADO DE UN ASESINATO}

El 14 de febrero de 1996, a media mañana, en su despacho de profesor en la Facultad de Derecho de la Universidad Autónoma de Madrid, fue asesinado por 
la banda terrorista ETA Francisco Tomás y Valiente. Yo era entonces el Decano de esa Facultad y el crimen se cometió a pocos metros de mi propio despacho. Puede imaginarse el dolor y la indignación que, en ese momento, experimentamos los miembros de la Facultad, en mi caso aumentado por la estrecha relación de amistad que con él tenía.

Pero, al margen de los sentimientos personales, aquel asesinato adquiría una significado más trascendente, ya que habían matado no sólo a un hombre, sino también, deliberadamente, a un símbolo: el de un ejemplar defensor de nuestra Constitución democrática que, de manera cabal, Tomás y Valiente había encarnado. No es de extrañar que, por ello, de inmediato, se produjera una firme reacción ciudadana, representada primero, ese mismo día, por la masiva y espontánea concentración que tuvo lugar delante de la fachada de la propia Facultad, donde miles de estudiantes, profesores y personal administrativo expresaron su repulsa acudiendo con las manos pintadas de blanco, una imaginería, la de las «manos blancas», que a partir de ese momento se mantendría como signo de combate civil frente a los ignominiosos atentados contra nuestro régimen de libertades. Actitud ciudadana repetida y aumentada dos días después en la inmensa manifestación que recorrió varias calles de Madrid condenando ese asesinato, y la que concurrió casi un millón de personas.

Porque Francisco Tomás y Valiente no había sido sólo un eminente historiador del Derecho, creador de una notable obra académica y una escuela de profesores de la más alta cualificación. Había sido, además, un gran hombre de Estado, del Estado constitucional y democrático de Derecho, al que sirvió de modo preeminente, de 1980 a 1992, como Magistrado del Tribunal Constitucional durante los primeros doce años de la vida de ese Tribunal, del que fue el segundo Presidente en los últimos seis años de su mandato, y poco después como Consejero de Estado, primero como Consejero electivo, en 1994, e inmediatamente como Consejero permanente desde 1995 hasta el día de su asesinato.

Su labor docente como profesor universitario, a la que con tanta vocación se dedicó desde que terminó la carrera de Derecho y obtuvo el doctorado, se vio necesariamente interrumpida en 1980 con su acceso al Tribunal Constitucional. Cuando, en 1992, terminó su mandato en esa institución volvió a la universidad, y allí permaneció hasta su muerte, pues mientras fue Consejero de Estado quiso simultanear ese cargo con la docencia. Precisamente unos días antes de que ocurriese la tragedia hablaba conmigo en el decanato expresándome su preocupación por el hecho de que, siendo ya Consejero permanente de Estado, iba a tener más difícil cumplir regularmente su función de profesor, pese a su deseo de no desvincularse de la Facultad.

Recuerdo que, para disipar esa preocupación, le dije unas palabras que nunca olvidaré: «Paco, no te preocupes, aquí harás lo que tú quieras y puedas, pero sigue viniendo, que los alumnos necesitan escucharte; siempre tendrás aquí tu despacho, donde además tan tranquilo podrás estar». ¡Qué lejos estaba yo de pensar que esa tranquilidad en su despacho de la Facultad que en mi conversación 
con él le auguraba quedaría violentada tan pronto, en ese mismo despacho, por unos asesinos!

Aquel día triste no sólo quitaron la vida a un gran profesor, sino también a quien había dedicado los últimos dieciséis años a defender la Constitución de manera eminente, en el Tribunal Constitucional, primero, en el Consejo de Estado, después, y en conferencias y publicaciones con las que nos prodigó desde que abandonó sus tareas jurisdiccionales. Pocas personas, como él, encarnaron entonces en España el prototipo de leal y alerta servidor de nuestro Estado constitucional.

Ese símbolo fue el que el terrorismo asesinó, consciente de que así mataba no sólo a un profesor universitario, sino a quien representaba todo lo que ese terrorismo odiaba: la libertad, la igualdad, la democracia y la justicia, esto es, el ideal de convivencia basado en el Derecho que la Constitución había establecido para todos los españoles. Asesinando a un profesor, en el propio recinto de la universidad, mostraba ETA su designio repugnante de «muera la inteligencia»; asesinando a un hombre que había servido de modo ejemplar a la democracia constitucional, mostraba ETA su designio ignominioso de «muera la libertad». En aquel trágico día del 14 de febrero de 1996 quedaron bien retratados la víctima y sus verdugos. La primera como ejemplo a seguir, los segundos como lacra que el Estado de Derecho debía exterminar.

Hoy, cuando han pasado veinte años de aquello, el ejemplo de Tomás y Valiente sigue vivo, pero la banda terrorista aún no ha sido liquidada, pese a que desde hace tiempo no actúa asesinando. Es de esperar que cuando ETA por fin desaparezca no se olvide el significado repugnante que siempre le acompañó y que no debe borrarse en la memoria política y ciudadana. Porque no basta, para el triunfo del Estado de Derecho, con que los culpables paguen sus crímenes, sino que es necesario que quede constancia para siempre de que sus designios aberrantes fueron derrotados. Eso es lo que nuestra democracia se merece y eso es lo que también se merece el recuerdo de quien, hace ya veinte años, fue la víctima de aquellos desalmados.

\section{FRANCISCO TOMÁS Y VALIENTE COMO MIEMBRO DEL TRIBUNAL CONSTITUCIONAL}

Jurista completo, su contribución a las labores del Tribunal Constitucional (de aquel espléndido primer Tribunal) y a la creación de su doctrina en los doce años que allí estuvo fue, sin duda, decisiva. Como decisiva fue también su presidencia del Tribunal, a la que imprimió las virtudes de su propio carácter personal: integridad, solvencia, autoridad y rectitud. Fue, desde luego, un digno sucesor de quien había sido el primer Presidente, don Manuel García-Pelayo, cuya personalidad señera era muy difícil de igualar, y a quien el propio Tomás y Va- 
liente calificó, en un precioso escrito, de hombre ejemplar, como ciudadano, como intelectual y como servidor del Estado.

Muchas veces se ha elogiado el papel que aquel primer Tribunal Constitucional desempeñó durante los primeros doce años de vida de la institución (pues doce años duró el mandato de algunos de los magistrados más influyentes en aquella tarea, entre ellos, destacadamente, Francisco Rubio Llorente y Francisco Tomás y Valiente). Los que integraron aquella primera fase del Tribunal Constitucional pusieron en marcha, con tino, la organización interna del Tribunal, adoptaron un estilo directo y claro de redacción de las sentencias y, sobre todo, fueron creando una doctrina absolutamente decisiva para dotar de eficacia jurídica al texto constitucional.

Hoy, nuestro sistema de derechos fundamentales no sería el que es, es decir, el de la plena efectividad de aquellos derechos, sin la labor que aquel primer Tribunal Constitucional llevó a cabo, que los dotó de plena eficacia, de concretos contenidos (por ejemplo, estableciendo todas las garantías procesales que podían derivarse del art. 24 de la Constitución) y que, en definitiva, les dio vitalidad jurídica en el ordenamiento español, haciendo que los ciudadanos los disfrutasen no sólo en razón del principio de legalidad sino, sobre todo, en razón del principio de constitucionalidad.

Su labor no fue menos importante en materia de organización territorial del poder. Aquel Estado autonómico que, a partir de las previsiones de la Constitución y de la aprobación de los sucesivos Estatutos de Autonomía, se presentaba como un sistema lleno de complejidades, pudo funcionar gracias a la doctrina que el Tribunal Constitucional fue produciendo, aclarando la distribución de competencias, deslindando la autonomía de la soberanía, buscando un equilibrio entre la igualdad y la diferencia, o si se quiere, entre la acción general del Estado y las capacidades de acción territorial de las Comunidades Autónomas, encauzando pacíficamente los conflictos; en fin, construyendo, en realidad, el Estado autonómico, que más que obra del desarrollo legislativo fue, sobre todo, creación del Tribunal Constitucional.

Es cierto que algunas de sus decisiones pudieron ser polémicas, así, por ejemplo, la Sentencia sobre la LOAPA, o la dictada sobre el asunto RUMASA, de la que arranca, por cierto, una criticable doctrina constitucional sobre los decretos-leyes que después el Tribunal, lamentablemente, no ha corregido. Pero, aparte de que el carácter criticable de algunas de sus decisiones sea lo normal en cualquier obra humana (y la del Tribunal lo es), lo que nunca podrá achacarse a aquel Tribunal es que no fundase suficientemente en Derecho sus decisiones. Todas ellas resultaron, a mi juicio, producto de una sólida motivación que, pudiéndose o no compartir por la crítica jurídica, les confería una innegable respetabilidad.

Por lo demás, la inmensa mayoría de las decisiones jurisprudenciales de aquel primer Tribunal, en todas las materias, recibieron una generalizada aceptación intelectual en el seno de la cultura jurídica española. Cumplió, sin duda alguna, y 
muy bien, su función de supremo aplicador e intérprete de la Constitución, convirtiéndola en una realidad viva para las instituciones públicas y los ciudadanos.

Ese fue el legado que aquel primer Tribunal nos dejó, y en la construcción de ese legado tuvo una importancia fundamental Francisco Tomás y Valiente, como Magistrado de aquella institución y como su segundo Presidente.

\section{FRANCISCO TOMÁS Y VALIENTE COMO CONSTITUCIONALISTA}

El tránsito de Francisco Tomás y Valiente por el Tribunal convirtió al historiador del Derecho en constitucionalista y, hay que añadir, en un buen constitucionalista, como es reconocido por todos los juristas españoles. De ello nos dejó muestras no sólo a través del ejercicio de su función jurisdiccional, sino también mediante publicaciones académicas señeras y artículos en periódicos, en los que resplandecía su acertado juicio, su equilibrada opinión y, sobre todo, su constante defensa de los valores que la Constitución proclama.

Su testimonio como constitucionalista queda patente, pues, no sólo en su labor jurisdiccional, sino en sus propias Obras Completas (seis volúmenes que alcanzan las ingente cifra de 5.506 páginas), donde, junto a sus importantes trabajos como historiador del Derecho, entre ellos su excelente manual de «Historia del Derecho español» (que en su última parte es, por cierto, una espléndida historia del constitucionalismo español) y algunos más específicos sobre aspectos concretos de nuestra historia jurídica e institucional, hay un gran número de ellos dedicados directamente al Derecho Constitucional.

Dejando aparte otras contribuciones menores sobre dicha materia, quiero destacar en ese ámbito sólo cuatro de sus libros: «El reparto competencial en la jurisprudencia del Tribunal Constitucional», que es una excelente monografía sobre la distribución territorial del poder, «Escritos sobre y desde el Tribunal Constitucional», que es una valiosa recopilación de trabajos académicos, «A orillas del Estado», donde se contiene una selección de sus artículos en la prensa, y «Constitución: escritos de introducción histórica», en el que, junto con trabajos sobre historia constitucional, se integran otros sobre el concepto de Constitución, la independencia judicial, la garantía de los derechos fundamentales y el Estado autonómico.

En los cuatro se muestra, como antes he dicho, el buen hacer del Tomás y Valiente constitucionalista, no sólo como jurista constitucionalista, sino más aún, como intelectual constitucionalista, esto es, como persona que dedica sus reflexiones, con rigor técnico, pero también con finura de espíritu, a estudiar, propagar y consolidar ese modo civilizado de convivencia que es el sistema constitucional, posiblemente la forma más adecuada que hasta ahora se ha construido para organizar a una comunidad política en igualdad y libertad. A esa noble tarea dedicó, principalmente, los últimos años de su vida, que tan tempranamente nos 
fue arrebatada cuando tanto cabía esperar de la continuidad de su magisterio intelectual y de su ejemplo personal.

\section{LA VALIDEZ ACTUAL DE SU FIGURA}

En estos momentos de zozobra por los que nuestra Constitución atraviesa, en los que, temerariamente, se pone en cuestión, por algunos, la grandeza de nuestra transición política y el valor del texto constitucional que los españoles supimos darnos en 1978, hubiera hecho mucha falta que Francisco Tomás y Valiente estuviese entre nosotros, explicando, con su autoridad, que hay que seguir luchando por lo que él luchó: conservar el gran pacto político de la transición y la vigencia de nuestra Norma Fundamental, que tiene muchas más virtudes que defectos, y que, incluso para eliminar estos últimos, no hay otro modo seguro y civilizado de hacerlo que respetando el procedimiento que la propia Constitución ha previsto para su reforma.

Pero sobre todo alertándonos de que, aunque se acometan reformas, debe conservarse siempre el sistema de valores y principios que a la Constitución le dan su auténtico sentido: la soberanía del pueblo, la democracia representativa, la división de poderes, los derechos fundamentales, el Estado de Derecho, la búsqueda constante de equilibrio entre la libertad y la igualdad. Ellos compendian el sistema estatal que, junto con el principio de autonomía territorial integrada en la unidad de la nación y la monarquía parlamentaria como clave de bóveda de ese sistema, rige en España desde hace treinta y seis años y que no podemos dejar que se lo lleven los malos vientos de coyunturas históricas dislocadas.

Desgraciadamente ya no está entre nosotros Francisco Tomás y Valiente, pero sí nos pueden servir, para hacernos fuertes frente a los disgregadores y los demagogos, las ideas que él nos dejó. Espigaré algunas de ellas y las cito: «Si alguien con bienintencionada ignorancia me preguntara en estos momentos qué es el Estado, yo le diría señalando la primera página de los periódicos del día: el Estado es eso que comienza a desmoronarse delante de nosotros. Tal proceso de descomposición no puede ser contemplado ni con indiferencia (pues no va a todos en ello nuestra propia convivencia ciudadana) ni con pasividad». Eso lo decía, aclaro, refiriéndose a unos momentos aún más difíciles que los de ahora, pero no deja de tener alguna aplicación a la actualidad.

Sigo con las citas: «la relación entre el todo (la nación constituida en Estado democrático y social de Derecho) y las partes que la componen (las Comunidades Autónomas) no es ni puede ser nunca de antagonismo, sino de integración». Dicho en 1984 y tan pertinente para lo que en ese ámbito ahora sucede. Acudo a otra más: «Es hipócrita la dicotomía entre sociedad civil sana y poder político corrupto, en primer lugar porque la corrupción se instala en la coincidencia de los más viles y encanallados elementos de una y otro, y en segundo lugar porque ni aquélla es del todo inocente ni todo el poder público está en manos de corruptos. 
Hay llamas purificadoras que pueden provocar incendios que todo lo queman: cuidado con tales pirómanos». Esta es de 1993, y no ha perdido actualidad.

Les proporciono otra, larga pero también de mucha actualidad (se escribió en 1994 y parece que no ha pasado el tiempo): «Seco, soleado y, sin embargo, tormentoso. No sé si será por aquello de que ya no llueve nunca, pero lo cierto es que el ambiente está sucio, cargado de palabras como dardos, de acusaciones gritadas, de condenas instantáneas, de insultos cruzados, de improperios que ocupan el lugar de los argumentos y las razones. El aire está enrarecido. La política como espectáculo agresivo que se representa para que un público ausente lo vea y oiga sustituye a la política como acción de gobierno criticada por oponentes en un debate racional celebrado en el foro donde el pueblo está presente porque está representado. Pienso que el espectáculo empieza a cansar. Menos insultos y más razones. Menos sospechas y más datos. En un clima tan agresivo acaso los políticos se acostumbran a respirar, pero no los ciudadanos. Nadie debe intentar destruir a nadie, porque esto no es una guerra, sino cabalmente la sustitución de la violencia por un tipo de artificios consistentes en reglas formales de procedimientos, urnas y votos. La democracia española comenzó en un clima de distensión y entusiasmo que no podía durar hasta el final de los tiempos porque, pasados los constituyentes, el consenso tenía que ser en parte sustituido por la confrontación de intereses. Pero urge resucitar, en cuanto sea posible, y lo es en alta dosis, un clima de respeto mutuo, de discusión sin desprecio a las personas, de menos insultos, menos acusaciones y menos condenas apresuradas. Y ello no sólo por cuestión de principios propios y respeto a derechos ajenos, sino también en atención a un cálculo pragmático: el ciudadano se está cansando de este clima. Tiene ganas de respirar un aire algo más limpio y más fresco. Quien acierte a cambiar el clima, ganará votos, porque a nadie le gusta vivir en perpetua tormenta».

Y, en fin, una última cita, también de 1994: «Se es un hombre de Estado cuando se comprende que sólo desde un determinado tipo de Estado en también un determinado tiempo y país es posible la paz, la libertad en igualdad y la democracia como régimen preferible a cualquier otro, y cuando, partiendo de esa convicción, se acierta a construir aquello en lo que se cree. Se es un hombre de Estado cuando se comprende la necesidad de ese instrumento para lograr la paz y la libertad en la patria común, y cuando se trabaja para lograr y estabilizar esa construcción por encima de episodios pasajeros, de aspiraciones innobles, de reminiscencias de un pasado imposible como futuro».

Hoy, ante el ruido y las falsas apariencias que se extienden en nuestra vida pública, parece que no tenemos hombres de Estado así, pero confío en que surgirán si los ciudadanos comprometidos con la España constitucional y democrática mantenemos viva la enseñanza que Francisco Tomás y Valiente nos transmitió. $\mathrm{Si}$, como se decía en los primeros siglos de la Iglesia, el martirio es semilla de cristianos, hoy podemos confiar, parafraseando ese dicho, en que el martirio de Tomás y Valiente sea semilla de defensores de nuestro Estado constitucional y democrático de Derecho frente a quienes pretenden destruirlo. 
A la defensa, estudio y difusión de los valores constitucionales dedicó Francisco Tomás y Valiente los mejores y últimos años de su vida y a causa de ello sufrió una muerte ignominiosa. Murió en realidad por servir a esos valores, y en ese sentido le cuadra bien el calificativo de mártir civil. Ese, el del servicio a la Constitución, danto incluso su vida por ella, es el ejemplo impagable que nos ha legado. Fue, sí, un historiador notable, un profesor universitario modélico, un destacado cultivador del Derecho, pero, sobre todo, fue, como jurista, como intelectual y como servidor público, un verdadero hombre de Estado, del Estado constitucional democrático. Ojalá que, en estos tiempos de tribulación, ese legado no se pierda.

$* * *$

TITLE: Biographical sketch of Francisco Tomás y Valiente

ABSTRACT: Biographical sketch of Francisco Tomas y Valiente, historian, jurist and intellectual.

Resumen: Semblanza de Francisco Tomás y Valiente, historiador, jurista, intelectual y hombre de Estado.

KEY WORDS: Francisco Tomás y Valiente. Semblanza.

Palabras clave: Francisco Tomás y Valiente. Biographical sketch.

FECHA DE RECEPCIÓN: 20.03.2016 FECHA DE ACEPTACIÓN: 27.07.2016 